\title{
Editorial: Back to the roots
}

\author{
Mark Winands \\ Department of Data Science and Knowledge Engineering, Maastricht University, The Netherlands \\ E-mail:m.winands@maastrichtuniversity.nl
}

In the last issue of this volume, the ICGA Journal will go back to its roots by presenting several contributions on computer chess. We start by presenting two scientific articles that explore how to deal with draws in chess. The first article, Are Armageddon chess games implemented fairly? by Vladimir Vargas, describes the chess variant Armageddon chess, where in case of a draw Black is declared the winner. To compensate for this, White is given more time. The article presents a method that combines a 2750+ ELO human and engine chess play analysis to estimate the optimal time control so that the expected result of an Armageddon chess game is fair. The second article, Stalemate and 'DTS' depth to stalemate endgame tables by Karsten Müller and Guy Haworth, proposes that stalemate is a secondary goal in chess, superior to a draw by agreement or rule - but inferior to mate. The authors report the work of 'Aloril' who has created endgame tables holding both depth-to-mate and depth-to-stalemate data.

Next, this issue contains various reports on computer chess tournaments. The most noticeable are the ones on the 25th World Computer Chess Championship, the 9th World Chess Software Championship and the World Speed Chess Championship. These were held at the ICGA 2019 event in Macao, together with the Computer Olympiad and the conference on Advances in Computer Games. In the next volume there will be contributions discussing these other events, but we can already announce the ICGA 2020 event that will be held in conjunction with the 24th European Conference on Artificial Intelligence in Santiago de Compostela. The ICGA will organize there the 23rd Computer Olympiad, the World Computer Chess Championship and the International Conference on Computers and Games. The call for papers for the latter can be found in this issue as well.

It is also my pleasure that our new ICGA president Jonathan Schaeffer has contributed twice to this issue. In the first one, called An ICGA evaluation function, he discusses the current state of the ICGA regarding its chess events, Computer Olympiad, conferences and membership, among others. In the second one, he announces a call for papers for a special issue on Computer Chess Tournaments. It welcomes articles that recount the history and experiences of the early years of computer chess competitions.

Finally, I would like to give some words of gratitude to David Levy, who retired as president of the ICGA this summer. His contributions to computer chess and all his efforts to keep the ICGA running over the past decades have been of immense value. David, thank you all for this.

Mark Winands 